\title{
The Research on Comprehensive Performance Evaluation of Axial Piston Pump Based on AHP
}

\author{
Li-rong Wan, Yan-jie Lu $\mathbb{D}^{\mathbb{D}}$, Qing-liang Zeng $\mathbb{D}$, Kui-dong Gao $\mathbb{i}$, and Shou-bo Jiang
}

Institute of Mechatronics Control and Intelligent Equipment, College of Mechanical and Electronic Engineering, Shandong University of Science and Technology, Shandong 266590, China

Correspondence should be addressed to Kui-dong Gao; gaokuidong22@163.com

Received 24 April 2018; Revised 4 August 2018; Accepted 8 August 2018; Published 23 August 2018

Academic Editor: Frederic Kratz

Copyright (C) 2018 Li-rong Wan et al. This is an open access article distributed under the Creative Commons Attribution License, which permits unrestricted use, distribution, and reproduction in any medium, provided the original work is properly cited.

\begin{abstract}
The axial piston pump is an important industrial power element, and its performance directly affects the operation of the system. However, owing to its complex structure and harsh operational environment, the actual operational performance of the axial piston pump is difficult to be assessed accurately, which makes ensuring the normal operation of the hydraulic system difficult. To improve the evaluation method for an axial piston pump, a comprehensive performance evaluation system was proposed based on analytic hierarchy process (AHP), which could assess the performance of an axial piston pump on the basis of theoretical analysis, test, operator interaction, and application. Considering a model of load-sensitive axial piston pump with good operability as an example, the model development and simulation of the pump were carried out based on AMESim and the pump was tested using a developed performance test bed for axial piston pump. The weights of factors in the evaluation system were determined on the basis of the simulation results, analyses, and calculation. The above results were used to comprehensively analyze the tested pump and design a set of comprehensive performance evaluation software. The evaluation result was nearly identical to the actual usage, which verified the feasibility of the designed evaluation system.
\end{abstract}

\section{Introduction}

Axial piston pumps are widely used in industrial production as important power elements, and the performance of the pump directly affects the working condition of the hydraulic system. Therefore, it is important to accurately assess the working performance of the axial piston pump. Considering the complexity of the structure of the axial piston pump and the types of fault that could occur in it, as a kind of multiobjective analysis method, the AHP can satisfy the requirements of performance assessment and failure prediction for the pump. Yang et al. proposed a multiparameter evaluation method for oil pump unit, which used Failure Mode and Effect Analysis to select the evaluation indexes, AHP to calculate the weights of the indexes, and fuzzy comprehensive evaluation to assess the state of the pump unit [1]. Lin et al. proposed a failure prediction method for pump in aircraft based on fuzzy comprehensive evaluation and AHP [2]. In addition to the AHP, some researchers proposed performance evaluation methods employing other approaches. Bei et al. presented a method for assessing the performance and diagnosing the faults of hydraulic pumps, based on the wavelet packet transform and self-organizing mapping neural network [3]. Selvakumar J. et al. determined the key parts of centrifugal pump and analyzed the reliability by mathematical modeling and FEM analyses [4]. Xiaochuang Tao et al. introduced a method to evaluate the performance and diagnose the fault of rotating equipment based on the Fisher discriminant analysis and Mahalanobis distance [5]. By using proposing assessment methods, Ding et al. collected and processed the vibration signal of hydraulic pumps to monitor their working condition in real time and diagnose the faults of the pumps $[6,7]$. Most of these studies aimed at the operating state and fault diagnosis of hydraulic pumps, but only a few proposed comprehensive and systematic assessment schemes for the working performance of hydraulic pumps, or even special assessment methods for the axial piston pumps.

A systematic evaluation scheme should be based on theoretical analysis. At present, the relevant studies are usually focused on building mathematical models and simulating the 
structural influence on axial piston pumps using simulation software. Cui et al. simulated a load sensing variable pump and proposed a structure optimization scheme to reduce the response time and enhance its dynamic performance [8]. Alessandro Roccatello et al. carried out the cosimulation of a variable displacement axial piston pump using AMESim and ADAMS, and compared the simulation and experiment results [9]. Zhang et al. used the virtual prototype technology to develop the 3D virtual model of an axial piston pump and analyzed the flow ripple, pressure ripple, motion principle, and stress of the middle shaft and piston [10]. Xu et al. studied axial piston pumps using the radial micromotion and pressure distribution in combination with a numerical simulation model and the flow pulsation under steady and transit states; they also proposed a new pressure distribution method to decrease the pulsation of flow rate and torque and improve the volumetric efficiency [11-14]. However, no existing study has evaluated the structure of an axial piston pump with a comparative simulation concerning the influences of various structure parameters on the pump performance.

Owing to the influence of the machining accuracy and error in production processes, the actual performance of a piston pump is quite deviated from the theoretical simulation results, which makes the development of a corresponding performance test bed and test scheme necessary. Guo et al. designed and built a hydraulic pump reliability test bed that could predict the service life of the pump and optimized the sampling period of the reliability test [15]. Wang et al. proposed a new test method for the working characteristic of hydraulic pumps, which could predict the performance parameters of the tested pump using the developed mathematical model and obtain the service performance with a small number of test data [16]. Some researchers developed corresponding test equipment on the basis of simulations to study the performance of piston pumps and the influence of partial structure on overall pump performance $[17,18]$. It can thus be concluded that only few studies have reported on the test scheme for the performance of axial piston pumps and the design of the corresponding test bed. During the actual operation process, the performance of axial piston pump is significantly influenced by the working environment and human factor, which makes it necessary to study the performance test scheme of axial piston pumps.

To overcome the knowledge gap in existing, an evaluation model for the comprehensive performance of axial piston pump was established based on the AHP by considering the structure, performance test, and practical operation of the pump. In Section 2, the performance evaluation system of the axial piston pump was described. In the rest of the paper, the analysis of the parts of the system was described considering a certain type of axial piston pump. The influences of different structures on the pump performance were compared by simulation and were described in Section 3. In Section 4, the use of the performance test bed for the selected pump was detailed. In Section 5, on the basis of the analysis and test data presented in Sections 3 and 4, the performance assessment conducted for the chosen pump using the evaluation system by calculation and analysis was described. Conclusions are drawn in Section 6.

\section{Evaluation Model of Comprehensive Performance}

AHP is a multiobjective decision analysis method that combines qualitative and quantitative analyses. The principle of AHP is to categorize all the influence factors of a complex issue into interconnected and ordered levels according to relevance, compare and judge the importance degrees of the factors among the same layer, calculate the weights of factors using a matrix, and finally obtain the comprehensive analysis model.

In this study, the comprehensive performance of an axial piston pump was considered the goal level. Based on the research and analyses concerning the design of the structure, production, test, and operation process of the selected model of a load-sensitive axial piston pump that has good operability, the structure parameters, results of ex-work tests, technical support and working condition, and technical level of operators were considered first-grade evaluation indexes, and every index contained several second-grade indexes.

The structure parameters directly influence the performance of an axial piston pump. These influences were obtained by simulation with hydraulic simulation software AMESim. The flow coefficient of the pump in steady-state operation under different simulation conditions was calculated using the flow pulsation formula (1) [19].

$$
\delta_{\mathrm{Q}}=\frac{Q_{\max }-Q_{\min }}{Q_{\max }}
$$

where $\delta_{Q}$ is the flow pulsation and $Q_{\max }$ and $Q_{\min }$ denote the maximum and minimum flow rates in steady condition, respectively. The structural evaluation criterion was delimited by analyzing the theoretical working performance. Because of the errors in an actual production process, a hydraulic test bed was designed and built, and an ex-work test was conducted with the considered pump to determine its actual performance. The actual operational environment was also researched and analyzed to evaluate the influences of working conditions and human factors on the pump performance in actual operation.

Based on the hierarchical evaluation model shown in Figure 1, the importance degrees of factors among the same layer were measured by using the relative scale presented in Table 1 [20] to construct the judgment matrixes for each level.

To ensure that the results of the AHP are reasonable, the consistency of the obtained judgment matrix should be verified by calculating the consistency ratio $\mathrm{CR}$

$$
C R=\frac{C I}{R I}
$$

where the consistency index CI $=\left(\lambda_{\max }-n\right) /(n-1)$, in which $\lambda_{\text {max }}$ is the largest eigenvalue and $n$ is the matrix size; the average random consistency RI was acquired by relative table lookup [20]. The matrix consistency is acceptable if CR does not exceed 0.1; otherwise, the judgment matrix should be revised and improved.

If the matrix passed the consistency check, normalization processing of the eigenvector corresponding to the largest 


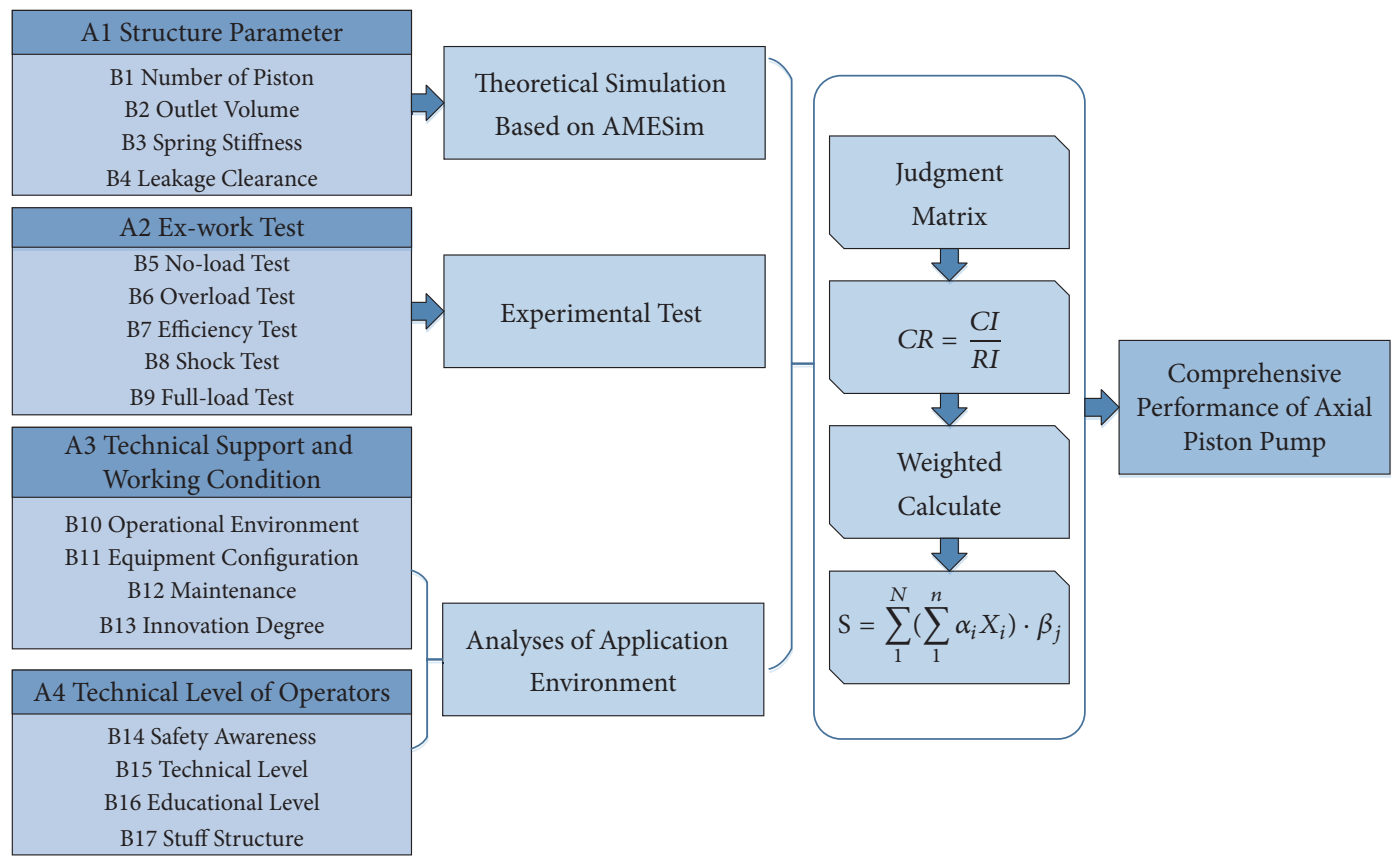

FIGURE 1: Comprehensive performance evaluation system of axial piston pump.

TABLE 1: Relative scale.

\begin{tabular}{lc}
\hline Numerical rating & Definition \\
\hline 1 & Equally preferred \\
3 & Moderately preferred \\
5 & Strongly preferred \\
7 & Very strongly preferred \\
9 & Extremely preferred \\
$2,4,6,8$ & The assessment falls between two levels \\
\hline
\end{tabular}

eigenvalue was carried out to obtain the weights of the factors. All factors of the tested pump were assigned and weighted and calculated to obtain the comprehensive performance score of the tested pump using the below formula.

$$
S=\sum_{1}^{N}\left(\sum_{1}^{n} \alpha_{i} X_{i}\right) \cdot \beta_{j}
$$

where $S$ is the total score of the comprehensive performance evaluation of the axial piston pump, $X_{i}$ denotes the score of a single second-grade index, $\alpha_{i}$ is the weight of the secondgrade index, and $\beta_{j}$ is the weight of the first-grade index.

After the calculation of the evaluation score, the tested pump was rated according to the score as follows: Grade A (score above 100), Grade B (score within 70-85), Grade C (score within 60-75), and Grade D (score below 60).

\section{Theoretical and Simulation Analyses Based on AMESim}

The simulation of the axial piston pump was carried out using AMESim and the simulation results were compared and analyzed to determine the influences of the structural parameters on the pump performance. The analysis results were used to define the scoring methods and standards for the factors of the first-grade index "structure parameter."

3.1. Simulation Model of Axial Piston Pump. A load-sensitive axial piston pump works in the following manner: the pistons reciprocate in the cylinder and the swash plate angle changes with different loads to change the volume of the piston cylinder; thus, the output flow can be changed with load demand. The working principle of a load-sensitive pump is shown in Figure 2 [21].

According to the mechanism of the load-sensitive pump, a simulation model including seven pistons was built using AMESim, and it is shown in Figure 3. The main components and structures are marked in the lower right. Models (a)(c) were chosen from the axial piston pump library and (d)(e) were developed using primarily the components from the HCD library.

The working parameters were set according to the tested pump to simulate the influence of important structural parameters on the pump performance. For the pump model, the rated speed was $1800 \mathrm{r} / \mathrm{min}$, the rated pressure was 25 $\mathrm{MPa}$, and the rated displacement was $180 \mathrm{~mL} / \mathrm{r}$. Because the 
TABLE 2: Main global parameters.

\begin{tabular}{lcc}
\hline Title & Value & Unit \\
\hline radial position of the pump piston & 30 & $\mathrm{~mm}$ \\
clearance on piston diameter & 0.03 & $\mathrm{~mm}$ \\
diameter of piston & 6 & $\mathrm{~mm}$ \\
inner diameter of the servo cylinder & 5 & $\mathrm{~mm}$ \\
swash plate angle & 17 & degree \\
\hline
\end{tabular}

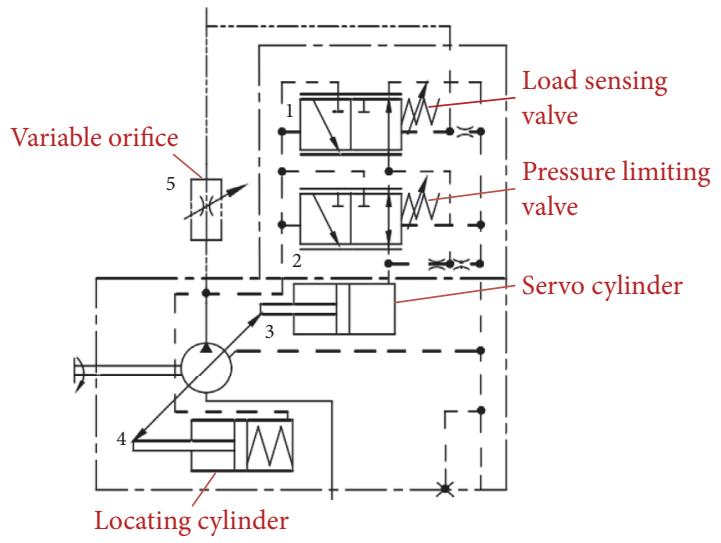

FIGURE 2: Principle of load-sensitive pump.

number of components used in the simulation model was large and some parameters were used in the calculation, several global parameters were used for some components. The main global parameters in the model are listed in Table 2.

\subsection{Influences of Structural Parameters on Working Perfor-} mance. The main structural parameters discussed in this paper include the number of pistons, outlet volume of pump, spring stiffness of locating cylinder, and the radial leakage clearance between the piston and the hole in cylinder. By default, the number of pistons was 7 , outlet volume was 15 $\mathrm{cm}^{3}$, spring stiffness was $10 \mathrm{~N} / \mathrm{mm}$, and leakage clearance was $0.03 \mathrm{~mm}$. In the comparison simulations, only the studied structure or parameter was changed while others remained constant.

3.2.1. Influence of Number of Pistons. Six types of piston pump models with 6-11 pistons, respectively, were built. To eliminate the influence of nonessential factors on the flow, the main structural parameters were kept invariant besides the number of piston and the rated flow of each pump was set as 324 $\mathrm{L} / \mathrm{min}$. The models were simulated and the output flows are shown in Figure 4 . The pulsation rates of the models were calculated according to formula (1) with the steady-output flow data and are shown in Figure 5. The overshoot of each output flow was calculated as

$$
M_{p}=\frac{Q_{e x}-Q_{a v}}{Q_{a v}}
$$

and these are shown in Figure 6. In the formula, $M_{p}$ is the overshoot of flow rate, $Q_{e x}$ is the extremum flow in the initial stage, and $Q_{a v}$ is the average flow. The simulation results show that (1) the flow pulsation rate tended to decrease with the increase in the number of pistons, which meant that a large number of pistons contributed to flow stability; (2) when the number of pistons was large, the slope of the pulsation curve decreased, indicating that the number of pistons had less influence on flow pulsation. Comparing the simulation result of each group, the piston pumps reached steady state at approximately $0.04 \mathrm{~s}$ and the change in the number of pistons had little influence on the time required for stabilization. As seen from Figure 6, the increase in the piston number of pistons led to the approximate linear growth of the overshoot, which increased the hydraulic impact of the pump and shortened the service life.

3.2.2. Influence of Outlet Volume. With other parameters set to their default values, the models with outlet volume of $5 \mathrm{~cm}^{3}, 10 \mathrm{~cm}^{3}, 15 \mathrm{~cm}^{3}$, and $20 \mathrm{~cm}^{3}$ were simulated, and the output flow curve of the pumps is shown in Figure 7. The flow pulsation rates calculated with formula (1) were 0.01296 , $0.073,0.0502$, and 0.0382 when the outlet volumes were 5 $\mathrm{cm}^{3}, 10 \mathrm{~cm}^{3}, 15 \mathrm{~cm}^{3}$, and $20 \mathrm{~cm}^{3}$, respectively. The simulation results showed that increasing the outlet volume of piston pump could effectively reduce the flow pulsation. When the outlet volume increased from $5 \mathrm{~cm}^{3}$ to $20 \mathrm{~cm}^{3}$, the settling time increased from approximately $0.2 \mathrm{~s}$ to $0.5 \mathrm{~s}$.

3.2.3. Influence of Spring Stiffness. The spring stiffness of the locating cylinder was set as $10 \mathrm{~N} / \mathrm{mm}, 25 \mathrm{~N} / \mathrm{mm}, 35$ $\mathrm{N} / \mathrm{mm}$, and $40 \mathrm{~N} / \mathrm{mm}$, and the corresponding models were simulated. The output flow curves of models with different spring stiffness and the corresponding flow pulsation rates are shown in Figures 8 and 9, respectively. It can be seen from the figures that when the spring stiffness was less than $25 \mathrm{~N} / \mathrm{mm}$, the change in spring stiffness only slightly affected the average value of flow rate, but with the decrease in spring stiffness, the response time, overshoot, and pulsation rate decreased. However, with the increase in the spring stiffness, the pump output flow decreased noticeably compared to the rated flow and the flow pulsation rate and settling time increased; therefore, the spring stiffness should not be too large.

3.2.4. Influence of Clearance Leakage. With a small radial leakage clearance between the piston and the hole in cylinder, the difference between the compared simulations was not obvious. Therefore, the leakage clearance was set as $0.1 \mathrm{~mm}, 0.12 \mathrm{~mm}, 0.14 \mathrm{~mm}$, and $0.16 \mathrm{~mm}$, and the flow rate curves obtained by calculation corresponding to the different leakage clearance and flow pulsation rates are shown in 


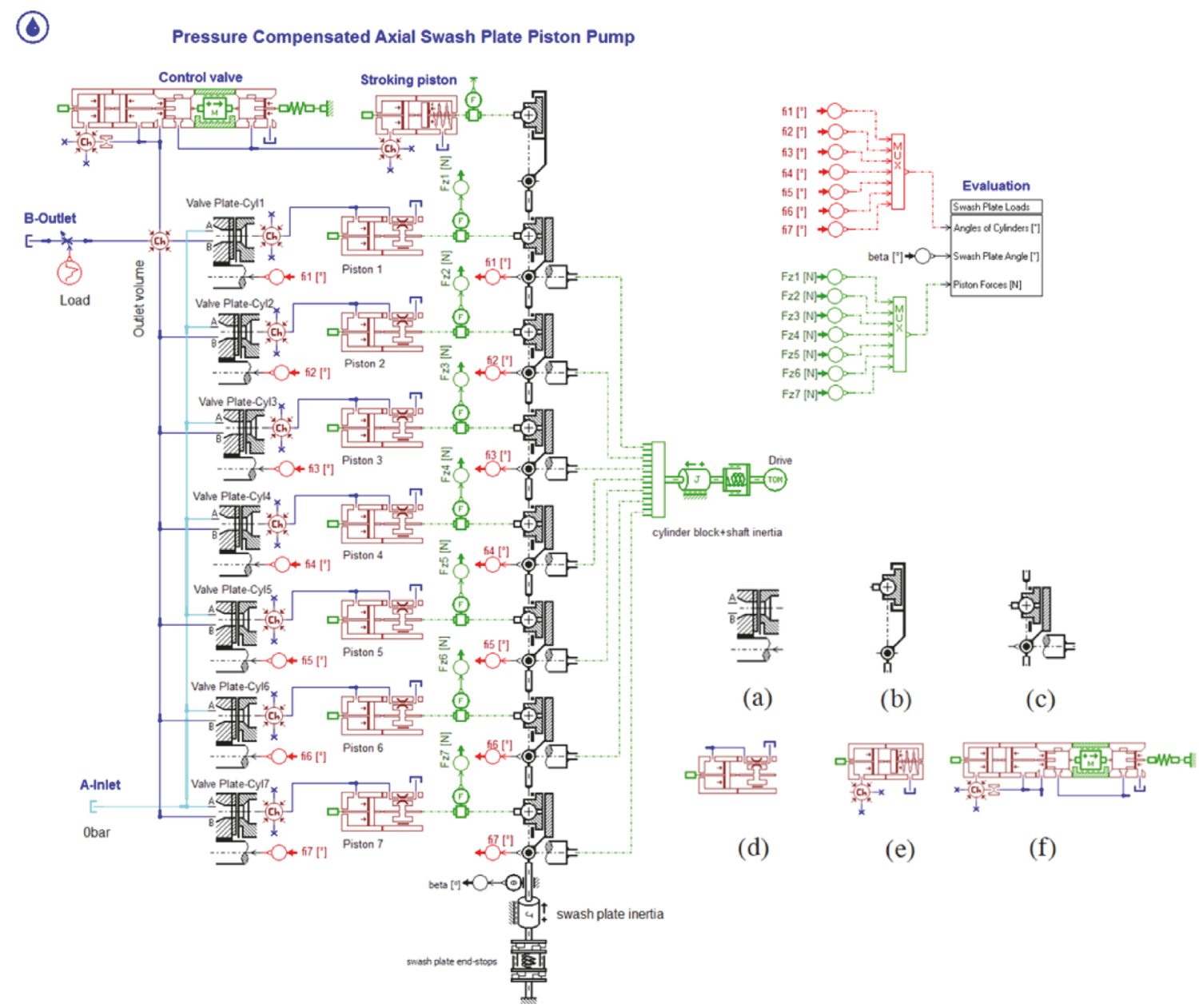

FIGURE 3: Simulation model of load-sensitive pump: (a) valve plate; (b) swash plate actuation mechanism; (c) swash plate connection mechanism; (d) piston; (e) locating cylinder; (f) servo cylinder.

Figures 10 and 11. The figures indicate that, with the increase in the clearance leakage, the flow overshoot reduced and the flow rate did so as well slightly. Excessive clearance led to the decrease in the flow rate and increase in the flow pulsation rate, which seriously impacted the working performance of the piston pump.

\section{Performance Testing of Piston Pump}

4.1. Design and Development of the Hydraulic System of Test $B e d$. Based on the investigation concerning the performance of the axial piston pump, the hydraulic test bed was required to complete the tests, no-load test, efficiency test, fullload test, overload test, and impact test, and collect the relevant data. In accordance with the Chinese National Test Standard JB/T 7043-2006, the hydraulic system of test bed was designed as shown in Figure 12:

1-tested axial piston pump; 2,20-motor; 3-hydraulic motor; 4,12,13,19,26-stop valve; 5,33-pressure sensor; 6,17,34temperature sensor; 7,8,22-relief valve; 9,28- check valve; 10,16-flowmeter; 11-cooler 14-electrical ball valve; 15,23,24fliter; 18-oil tank; 21-pump; 25-recycle tank for leaked oil; 27-vacuum sensor; 29 -electromagnetic directional valve; 30 electromagnetic proportional pressure valve; 31-torque and speed sensor; 32-liquid level sensor; 35-particle counter.

The hydraulic oil was sucked into tested pump 1 through stop valve 19. The outgoing high-pressure oil was split into two parts after check valve 28: one part went through the cartridge valve, while the other drove hydraulic motor 3 via stop valve 4 ; therefore, the high-pressure energy from the pump could be recycled as the input power of motor 2 to reduce the system energy loss. Components 5, 6, and 10 were used to detect the pressure, flow rate, and temperature at the pump outlet in real time. Components 7, 8, 29, and 30 constituted the loading unit. The main relief valve 7 was set at the maximum system pressure, manual loading could be applied by the combined use of valves 7 and 8, the impact test could be completed using the left and median positions of directional valve 27 cycle operation, and proportional loading could be performed using the right position of valve 27. Components 11, 12, 13, 14, 33 , and 34 composed the oil temperature detection and cooling device. With stop valve 12 closed and valve 14 conducted, cold water passed through electromagnetic valve 14 and plate cooler 11 to cool the system return oil. Components 20-24 


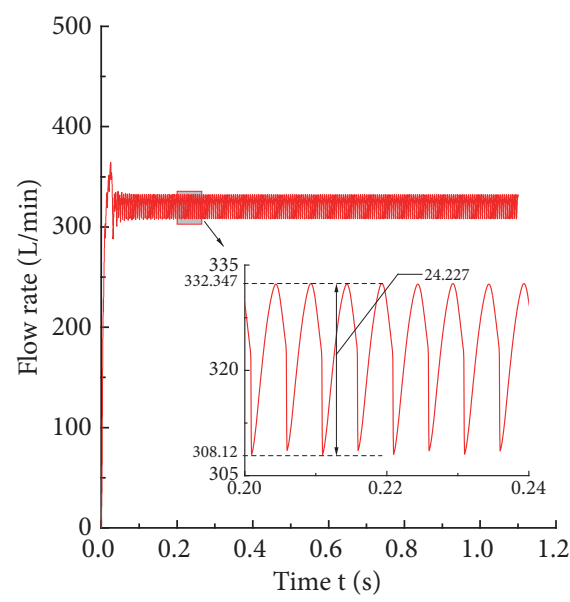

6 pistons

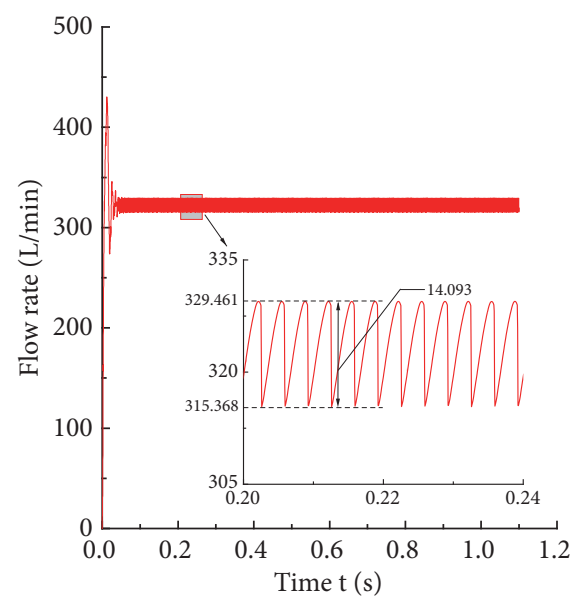

9 pistons

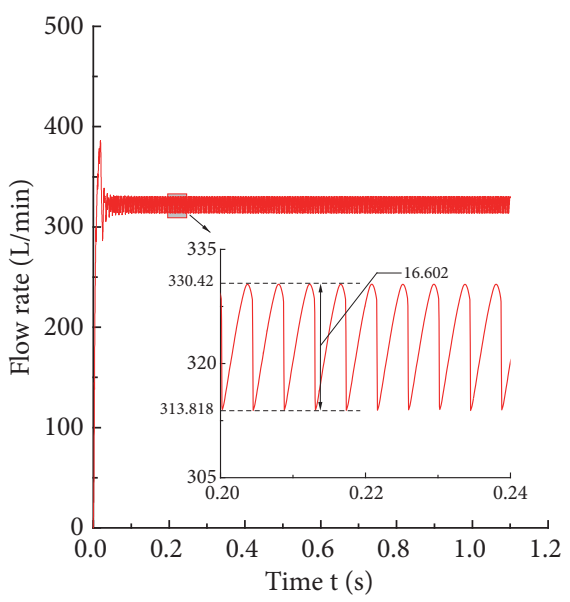

7 pistons

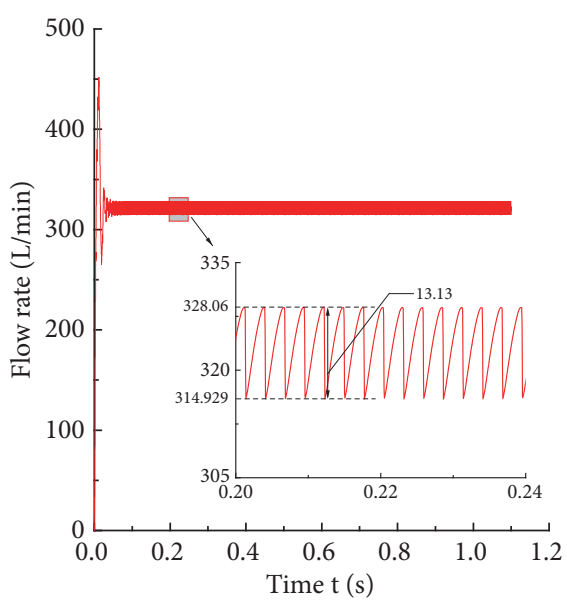

10 pistons

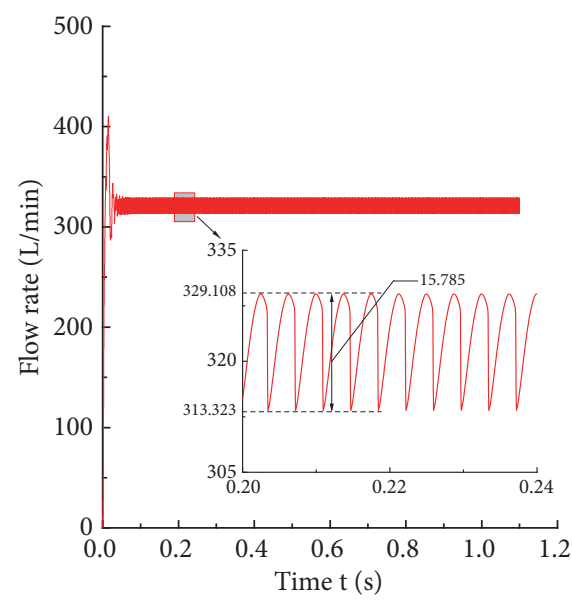

8 pistons

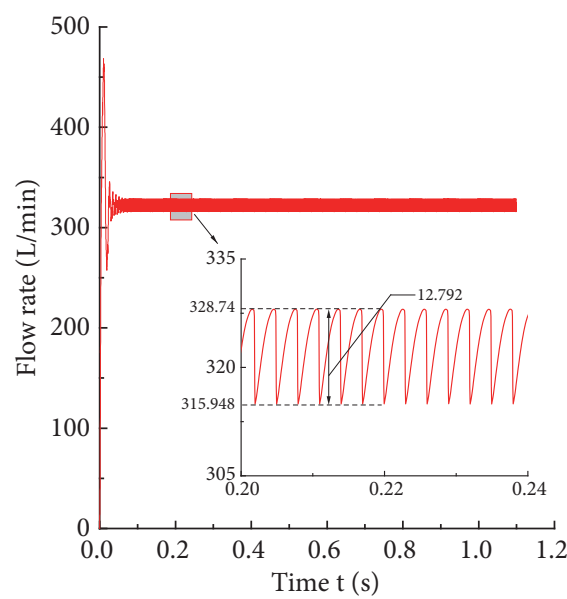

11 pistons

FIgURE 4: Time-flow curves with different piston numbers.

constituted the recovery system for dirty and leaked oil. All the leaked oil was collected in the lowest recovery tank 25 and flowed into tank 18 after coarse and fine filtering. Flowmeter 16 was installed at the drainage port to detect the flow leakage in real time. Vacuum sensor 27 was used to detect the vacuum of the pump inlet. The adsorption area of the pump was restricted by adjusting the opening of stop valve 19.

In order to improve the accuracy of the test data, a set of electronically controlled data acquisition system was adopted on the test bed. The signal required to be collected fell into digital and analog signals. After AD conversion, the analog signal could be displayed using the secondary instrument. The associated software system could collect signals such as those pertaining to flow rate and pressure using the ADAM acquisition module and could display the result curves. For safety purposes, the entire test bed was placed in a closed environment. The bottom of the test bed was interconnected to collect the leaked oil from the entire system into the oil tank, which ensured oil supply. The data acquisition interface and test bed are shown in Figure 13.
4.2. Performance Test Results. The performance test was carried out for the selected model of the piston pump with the built test bed. Owing to length limitation, only some main tests and relevant data are presented in this paper. To obtain the actual performance of the tested pump before use, the considered piston pump was of the same model and production batch as the chosen pump and unused to avoid the influence of actual operation on the pump performance.

For the tested pump, the rated speed was $1800 \mathrm{r} / \mathrm{min}$, the rated pressure was $25 \mathrm{MPa}$, and the rated displacement was $180 \mathrm{~mL} / \mathrm{r}$.

(1) No-Load Test. The test data of different time points from the no-load test is listed in Table 3. The data shows that the tested no-load value can satisfy the test requirement. Because the pump was constantly adjusting pressure during the movement process, the no-load displacement varied accordingly and a little suction might have occurred.

(2) Overload Test. Under the condition of the rated speed, $125 \%$ of the rated pressure, and the oil temperature at the 
TABLE 3: Data of no-load test.

\begin{tabular}{lccc}
\hline Item & \multicolumn{3}{c}{ Numerical results } \\
\hline Operation time $(\mathrm{s})$ & $30 \mathrm{~s}$ & $60 \mathrm{~s}$ & $90 \mathrm{~s}$ \\
Speed $(\mathrm{r} / \mathrm{min})$ & 1805 & 1809 & 1807 \\
Torque $(\mathrm{N} \cdot \mathrm{m})$ & 107.39 & 113.18 & 107.56 \\
Pressure at inlet $(\mathrm{KPa})$ & 3.81 & 6.07 & 5.44 \\
Pressure at outlet $(\mathrm{MPa})$ & 0.65 & 0.57 & 0.62 \\
Output flow $(\mathrm{L} / \mathrm{min})$ & 327.95 & 329.44 & 328.68 \\
Actual displacement $(\mathrm{mL} / \mathrm{r})$ & 181.69 & 182.11 & 181.89 \\
Temperature at outlet $\left({ }^{\circ} \mathrm{C}\right)$ & 57.32 & 61.63 & 64.93 \\
\hline
\end{tabular}

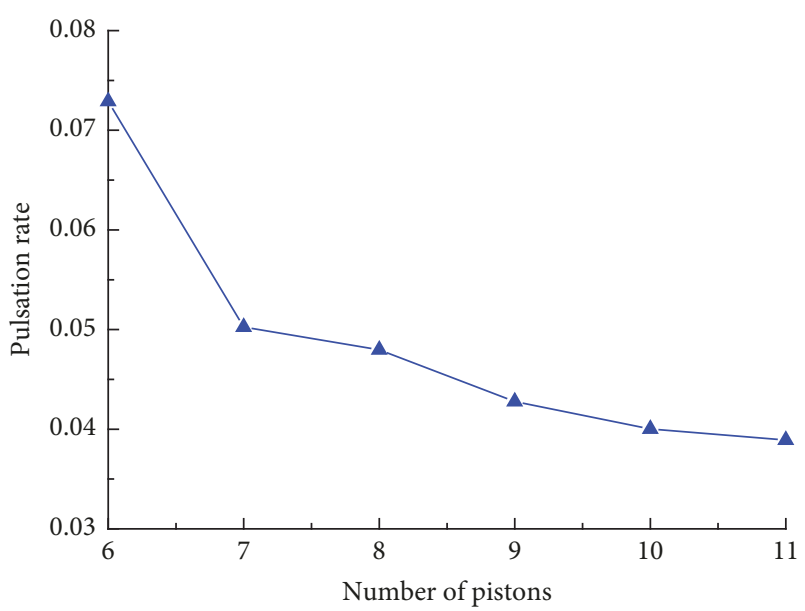

FIGURE 5: Flow pulsations with different piston numbers.

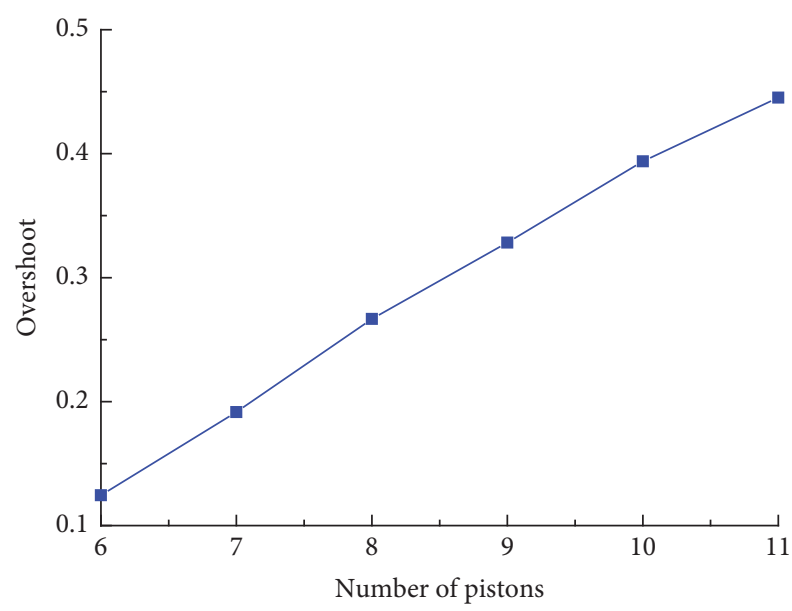

FIGURE 6: Flow overshoots with different piston numbers.

pump inlet of $30-60^{\circ} \mathrm{C}$, the tested pump was operated continuously for more than $1 \mathrm{~min}$ and the outlet pressure is shown in Figure 14, in which the curve was smoothed for convenient analysis. The test result indicated that, during the testing process, the steady-state value of the outlet pressure was 28.33 $\mathrm{MPa}$ and average pressure amplitude was approximately 0.14 $\mathrm{MPa}$; this meant that the operation process was stable with no anomaly and it satisfied the test requirement.
(3) Efficiency Test. With the rated speed, the data relevant to total efficiency and volumetric efficiency were measured when the pump outlet pressure was kept at 25\%, 40\%, 55\%, $70 \%, 80 \%$, and $100 \%$ of the rated pressure. The characteristic curves of the variation in total efficiency and volumetric efficiency with pressure are shown in Figure 15. With the increase in mechanical efficiency, the total efficiency increased with increasing pressure. Owing to the leakage loss and residual volume loss, the volumetric efficiency decreased with increasing pressure and finally stabilized at approximately $95.5 \%$. The test results met the test criteria.

(4) Impact Test. Under the condition of the rated speed, rated pressure, and $40 \%$ of rated power, the impact test was carried out with the impact wave set as test requirements. The obtained test curve is shown in Figure 16. In the test, the high and low pressures loaded on the tested pump were 27 $\mathrm{MPa}$ and $0.5 \mathrm{MPa}$, respectively, and the duration of the highpressure phase was approximately three-fifths of the impact cycle. The test process and results met the requirements.

(5) Full-Load Test. With the rated speed, rated outlet pressure, and maximum displacement, the tested pump was operated continuously. Owing to the large amount of data, the resultant curve was smoothed and is shown in Figure 17. As seen from the figure, the outlet pressure of the tested pump reached its maximum value at the beginning of operation, then the pressure and the slope of curve decreased gradually with oscillation until the pressure was stable at approximately 25.5 $\mathrm{MPa}$ and normal working conditions were reached.

The hydraulic test bed can also be utilized for the condition of noise, high-pressure, and other performance test item and met the requirements of the hydraulic pump test.

\section{Analyses of Comprehensive Evaluation for Working Performance}

Based on the proposed comprehensive performance evaluation system of the axial piston pump (see Figure 1) in Section 2, the relative scales of evaluation indexes in every level were determined according to a discussion with related experts and seasoned operators concerning the weight and relative importance of the influence factors. The relative scale determination of the factors of structural parameters was based on the judgment of their extent of influence on the pump performance according to the simulation results and 

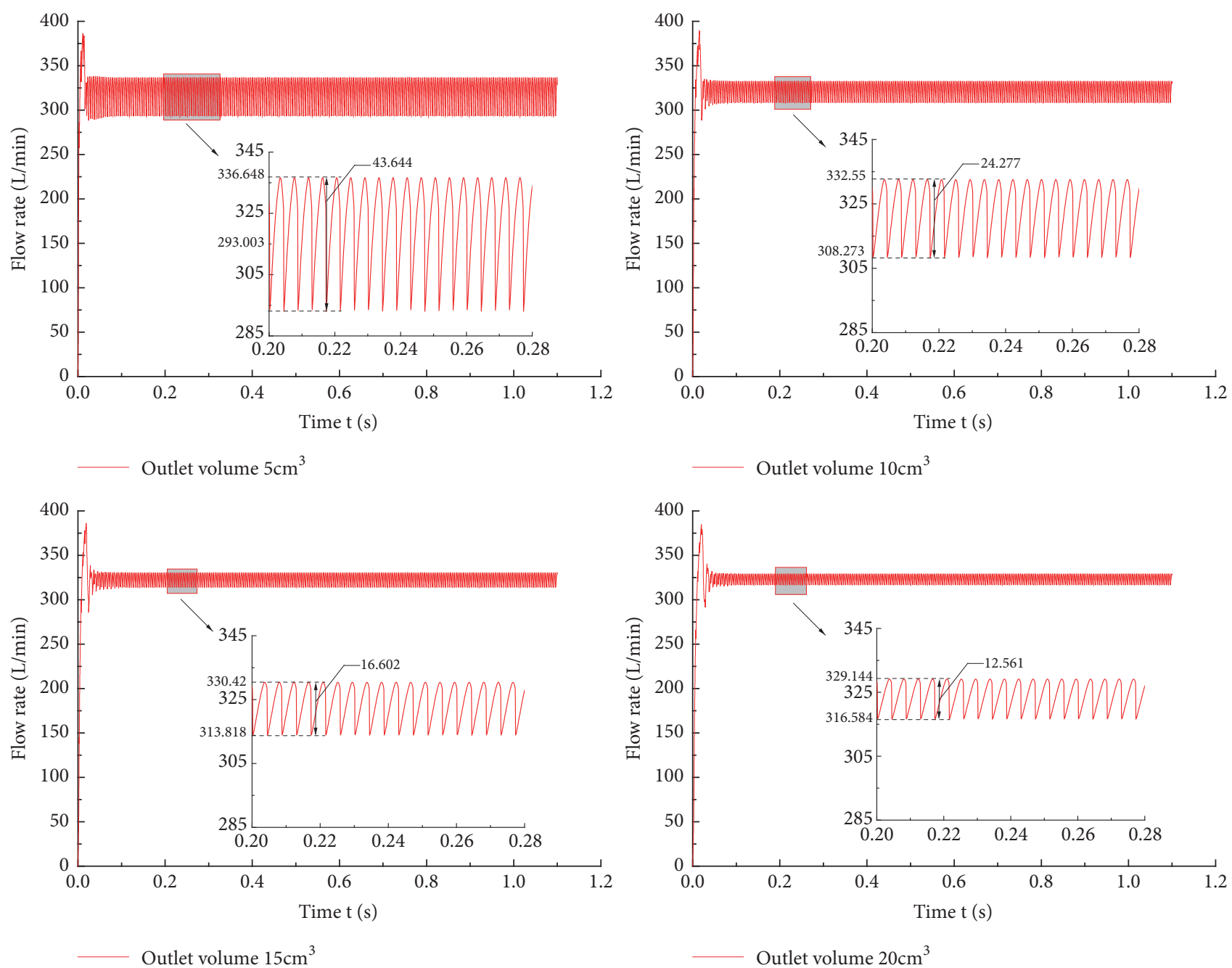

FIGURE 7: Time-flow curves with different outlet volume.

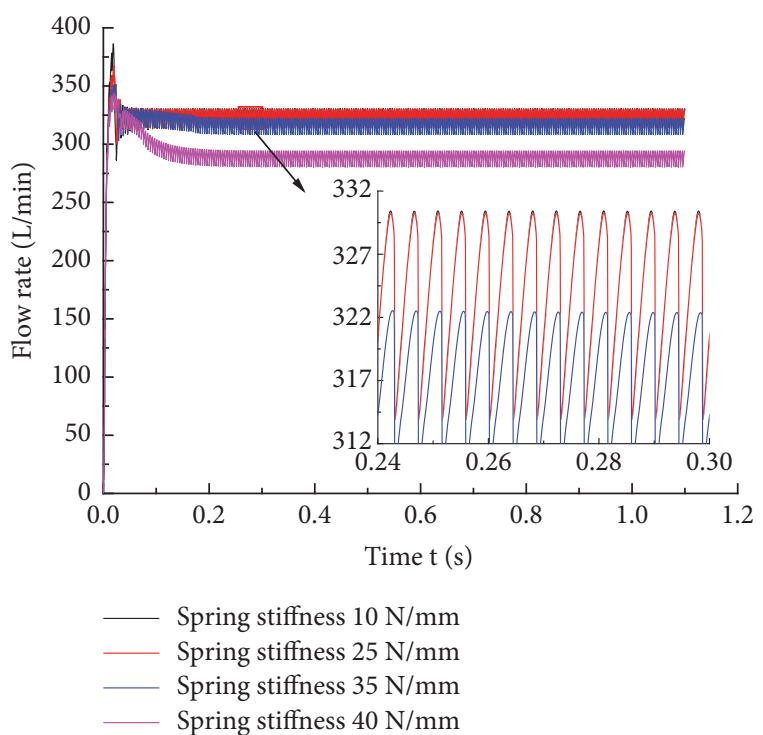

FIGURE 8: Time-flow curves with different spring stiffness. analyses presented in Section 3. The relative scales of each level are listed in Table 4.

The judgment matrixes corresponding to each level were obtained from the relative scales in Table 4 and solved using the square root method. The corresponding largest eigenvalues were $\lambda_{P}=4.1256, \lambda_{A 1}=4.2534, \lambda_{A 2}=5.1869, \lambda_{A 3}=$ 4.1569 , and $\lambda_{A 4}=4.1076$. The consistency ratios of the judgment matrixes were calculated with formula (2) as follows: $C R_{P}=0.0471, C R_{A 1}=0.0949, C R_{A 2}=0.0417, C R_{A 3}=$ 0.0588 , are $C R_{A 4}=0.0403$; all the values were less than 0.1 . The result of the consistency check indicated that the obtained matrixes were acceptable, and the weights calculated from the matrixes were feasible.

The eigenvector corresponding to the largest eigenvalue was processed by normalization to obtain the weights of the factors:

$$
\begin{aligned}
& P=\{0.5796,0.2553,0.1105,0.0546\}, \\
& A 1=\{0.1297,0.5093,0.0925,0.2685\}, \\
& A 2=\{0.0617,0.0617,0.1149,0.4612,0.2975\} \\
& A 3=\{0.152,0.0834,0.5086,0.256\}
\end{aligned}
$$


TABLE 4: Relative scales of each level.

\begin{tabular}{|c|c|c|c|c|c|c|c|c|c|c|c|c|}
\hline & & & \multicolumn{3}{|c|}{ A1 } & \multicolumn{2}{|c|}{$\mathrm{A} 2$} & \multicolumn{3}{|c|}{ A3 } & \multicolumn{2}{|c|}{ A4 } \\
\hline \multirow{5}{*}{$\mathrm{P}$} & \multicolumn{2}{|c|}{ A1 } & \multicolumn{3}{|c|}{1} & \multicolumn{2}{|c|}{3} & \multicolumn{3}{|c|}{6} & \multicolumn{2}{|c|}{7} \\
\hline & \multicolumn{2}{|c|}{ A2 } & & $1 / 3$ & & \multicolumn{2}{|c|}{1} & \multicolumn{3}{|c|}{3} & \multicolumn{2}{|c|}{5} \\
\hline & \multicolumn{2}{|c|}{ A3 } & \multicolumn{3}{|c|}{$1 / 6$} & & & & 1 & & & \\
\hline & \multicolumn{2}{|c|}{ A4 } & \multicolumn{3}{|c|}{$1 / 7$} & \multicolumn{2}{|c|}{$1 / 5$} & \multicolumn{3}{|c|}{$1 / 3$} & \multicolumn{2}{|c|}{1} \\
\hline & & B1 & B2 & B3 & B4 & & & B5 & B6 & B7 & B8 & B9 \\
\hline \multirow{6}{*}{$\mathrm{A} 1$} & B1 & 1 & $1 / 3$ & 2 & $1 / 4$ & \multirow{5}{*}{ A2 } & B5 & 1 & 1 & $1 / 2$ & $1 / 6$ & $1 / 5$ \\
\hline & B2 & 3 & 1 & 5 & 3 & & B6 & 1 & 1 & $1 / 2$ & $1 / 5$ & $1 / 5$ \\
\hline & B3 & $1 / 2$ & $1 / 5$ & 1 & $1 / 2$ & & B7 & 2 & 2 & 1 & $1 / 3$ & $1 / 4$ \\
\hline & \multirow[t]{3}{*}{ B4 } & 4 & $1 / 3$ & 2 & 1 & & B8 & 6 & 5 & 3 & 1 & 3 \\
\hline & & & & & & & B9 & 5 & 5 & 4 & $1 / 3$ & 1 \\
\hline & & $\mathrm{B} 10$ & B11 & $\mathrm{B} 12$ & B13 & & & B14 & & & B16 & B17 \\
\hline \multirow{4}{*}{ A3 } & B10 & 1 & 3 & $1 / 5$ & $1 / 2$ & \multirow{4}{*}{ A4 } & B14 & 1 & & & 4 & 5 \\
\hline & B11 & $1 / 3$ & 1 & $1 / 4$ & $1 / 3$ & & B15 & $1 / 3$ & & & 3 & 3 \\
\hline & B12 & 5 & 4 & 1 & 2 & & B16 & $1 / 4$ & & & 1 & 2 \\
\hline & B13 & 2 & 3 & $1 / 2$ & 1 & & B17 & $1 / 5$ & & & $1 / 2$ & 1 \\
\hline
\end{tabular}

P represented the goal level. A represented the first-grade index. B represented the second-grade index. The numbers were the relative scales.

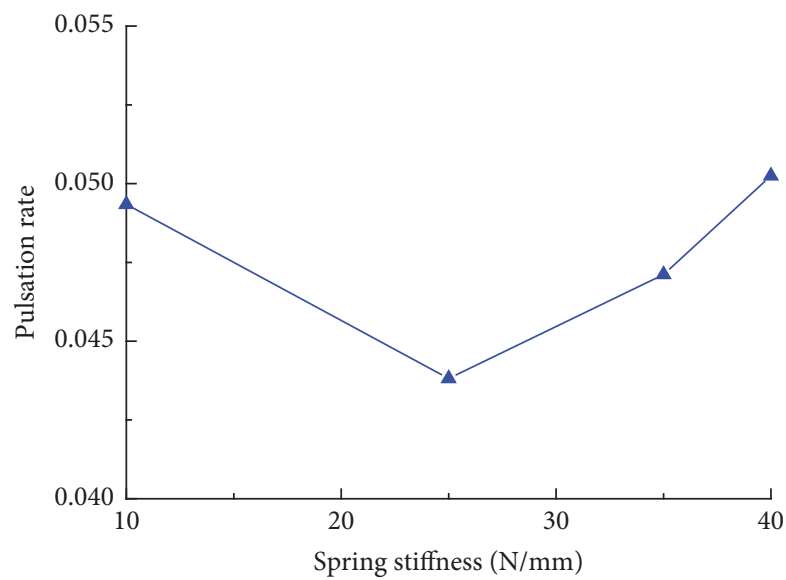

Figure 9: Flow pulsations with different spring stiffness.

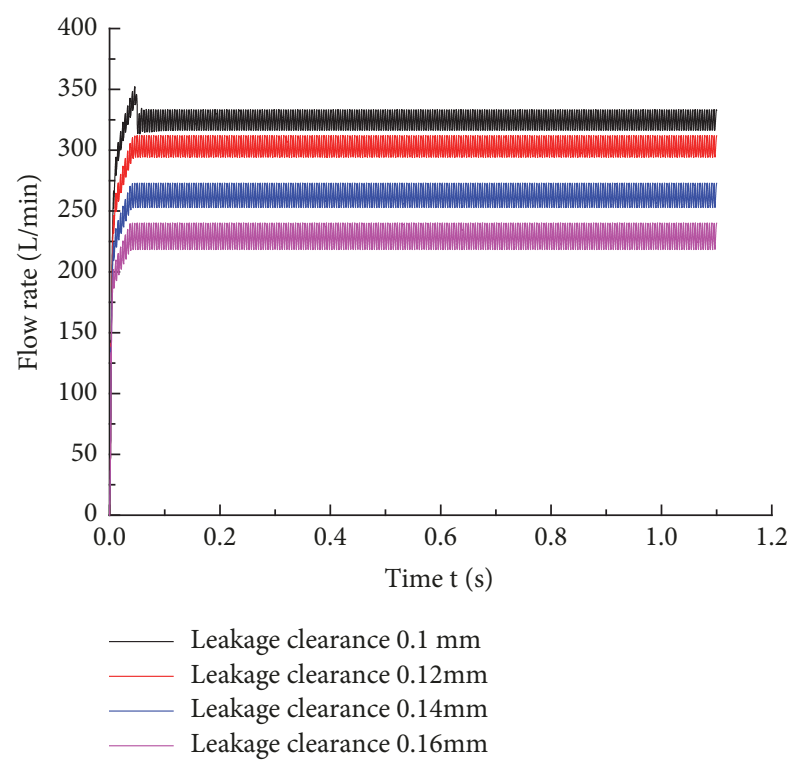

FIGURE 10: Time-flow curves with different clearance leakages.

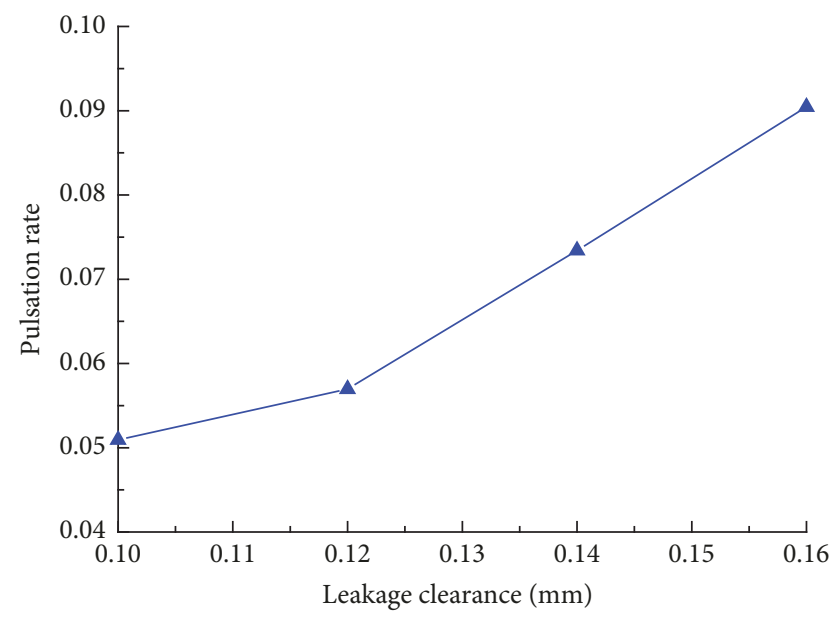

FIGURE 11: Flow pulsations with different clearance leakages.

$\mathrm{A} 4=\{0.5383,0.2562,0.1235,0.082\}$.

After the weight calculation, using the comprehensive performance of the tested pump as the goal, the single item scores of the factors in each level were calculated.

For the factors of the first-grades A1 and A2, the ideal conditions, marking criteria, and calculation formulas were required to be determined, and the item scores were calculated using the actual structure and test results of the tested pump. Considering the "no-load test" as an example, the Chinese National Standard stipulates that the no-load displacement of the tested pump should be in the range of $95-110 \% \mathrm{~V}$ when the nominal displacement is within $67-400$ $\mathrm{mL} / \mathrm{r}$. If the displacement cannot meet this standard, the score is 0 . When the standard is reached, the lower limit $95 \% \mathrm{~V}$ corresponded to a score of 60 and the upper limit $110 \% \mathrm{~V}$ corresponded to a score of 100 . The three groups of test result corresponding to different periods during stable operation 


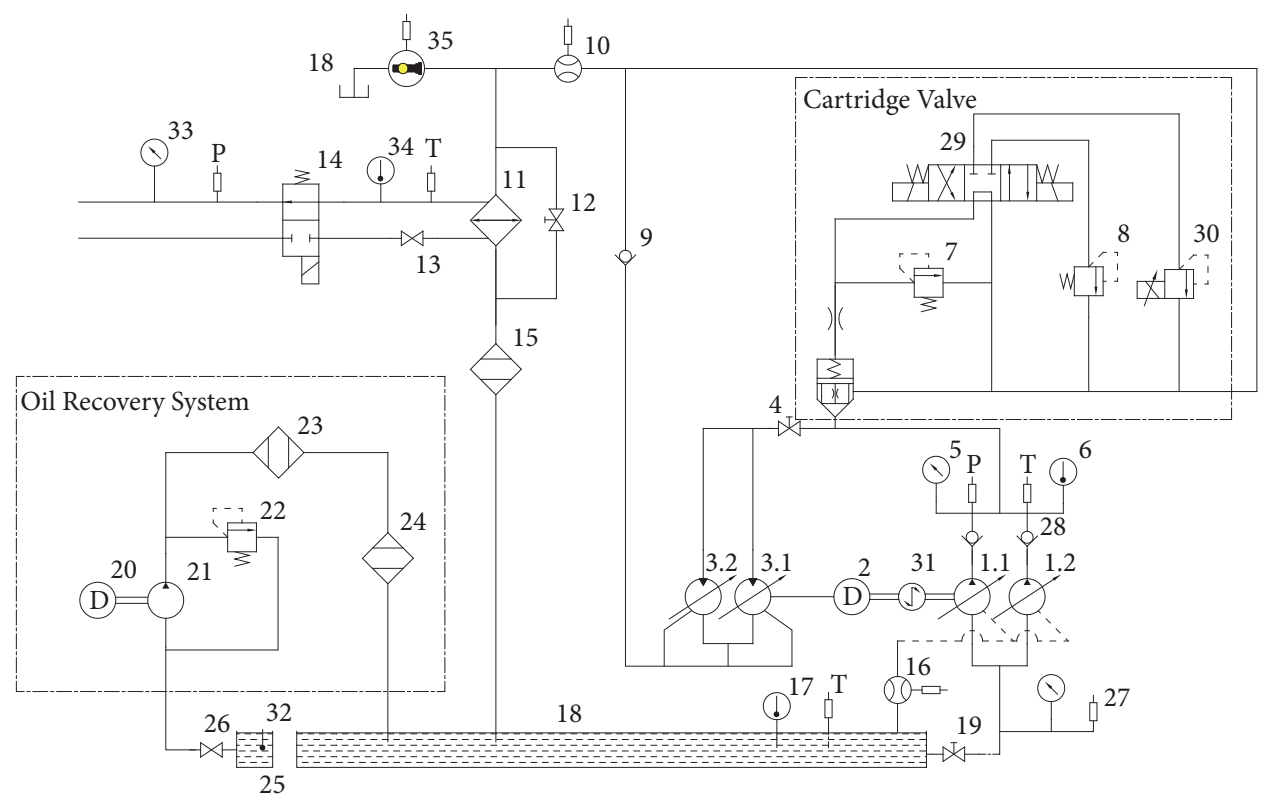

Figure 12: Hydraulic test system.

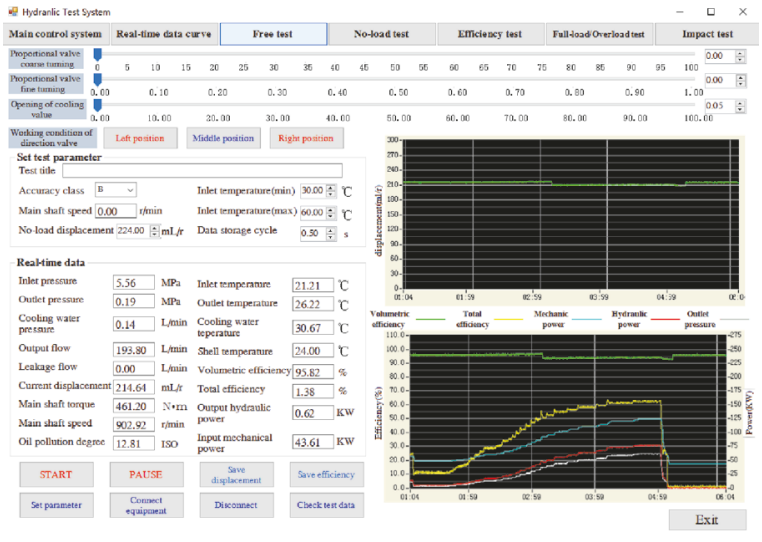

(a)

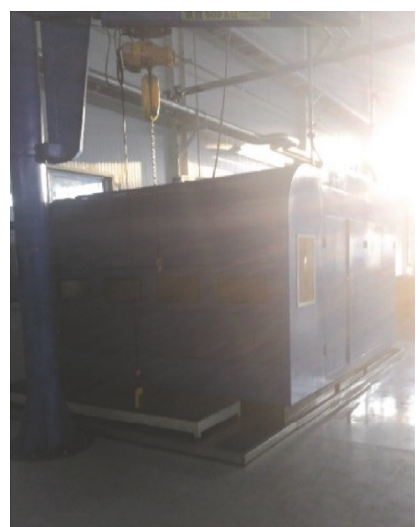

(b)

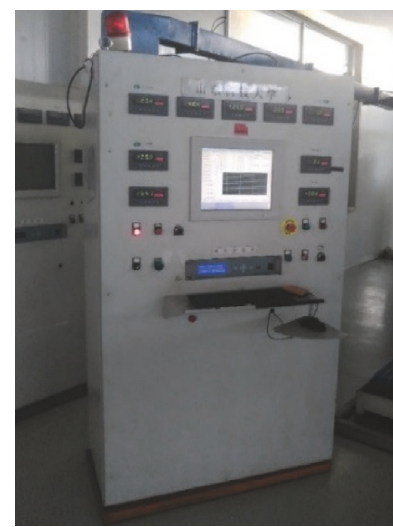

(c)

FIgURE 13: Data acquisition interface and site photos: (a) data acquisition interface and (b) and (c) site photos.

were averaged as the primary test result, and the score was calculated according to

$$
\mathrm{S}=\frac{V^{\prime} / V-95 \%}{15 \%} \times 40+60
$$

where $S$ is the item score, $V^{\prime}$ is the test displacement, and $V$ is the nominal displacement. The item score of the no-load test of the tested pump was 76.1 .

Because a large amount of relevant data could not be obtained, the factors of "technical support and working condition" were determined by qualitative and quantitative processing steps. The service and maintenance conditions of the tested pump were obtained by a survey of the application site. The item scores were marked by the professors and experts in the field and on the operation site.

To determine the scores of factors of the "technical level of operators," the educational background, professional title, and working status of the staff from design and production were recorded. The above information was quantized and weighted averaged to acquire the item scores. For instance, the factor of "technical level" was determined mainly according to the professional titles of the working group, in which professor corresponded to a score of 100, associate professor corresponded to a score of 90, intermediate title corresponded to a score of 80 , primary title corresponded to a score of 70, and no title corresponded to a score of 60 . The personnel condition was quantized, and the scores were weighted averaged to obtain the item score.

To simplify the calculation process, a set of software was developed based on $\mathrm{C \#}$ for analyzing and evaluating the comprehensive performance of the axial piston pump. The interface of software and the evaluation results of the tested pump are shown in Figure 18. The relevant nominal parameters of the tested axial piston pump, the judgment matrixes of 


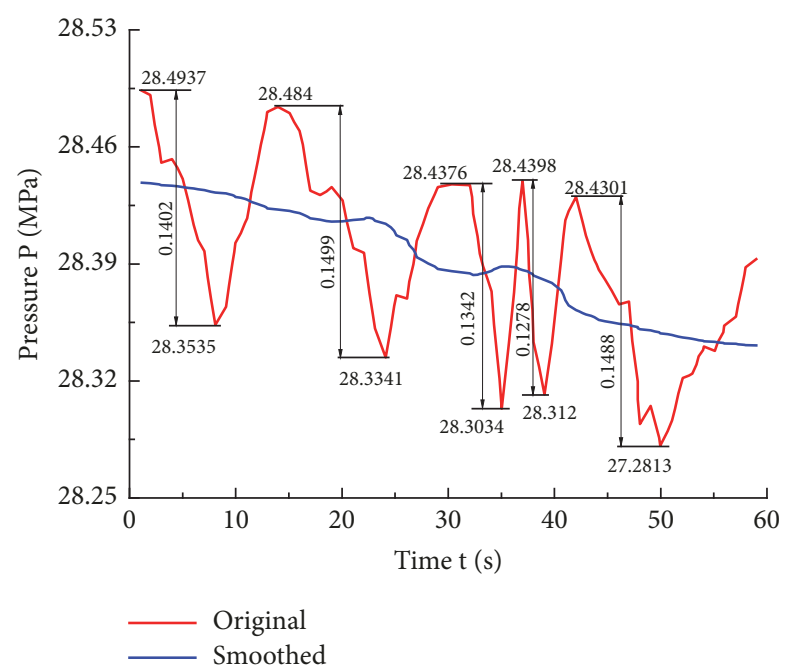

Figure 14: Result curve of overload test.

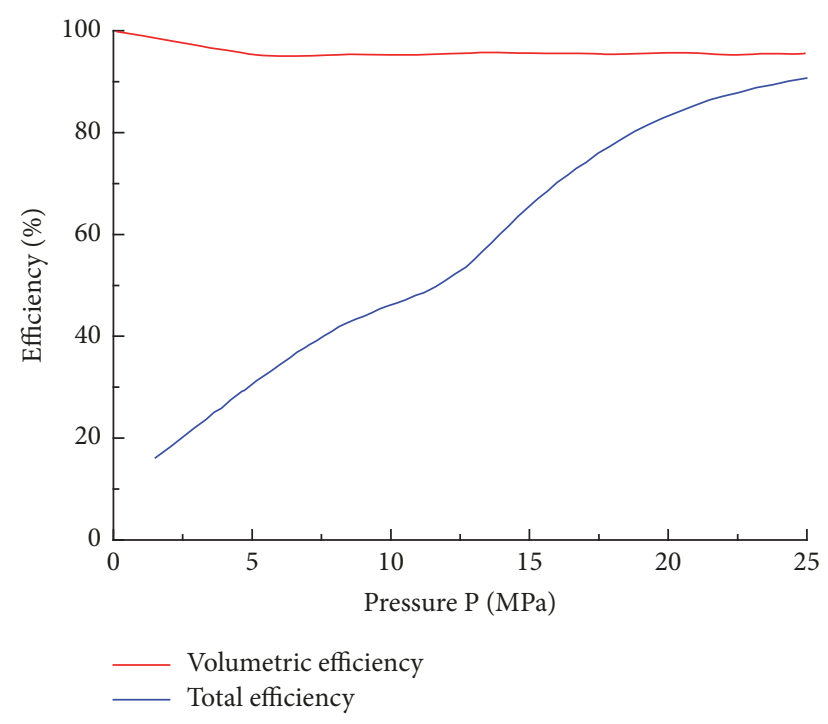

FIGURE 15: Result curve of efficiency test.

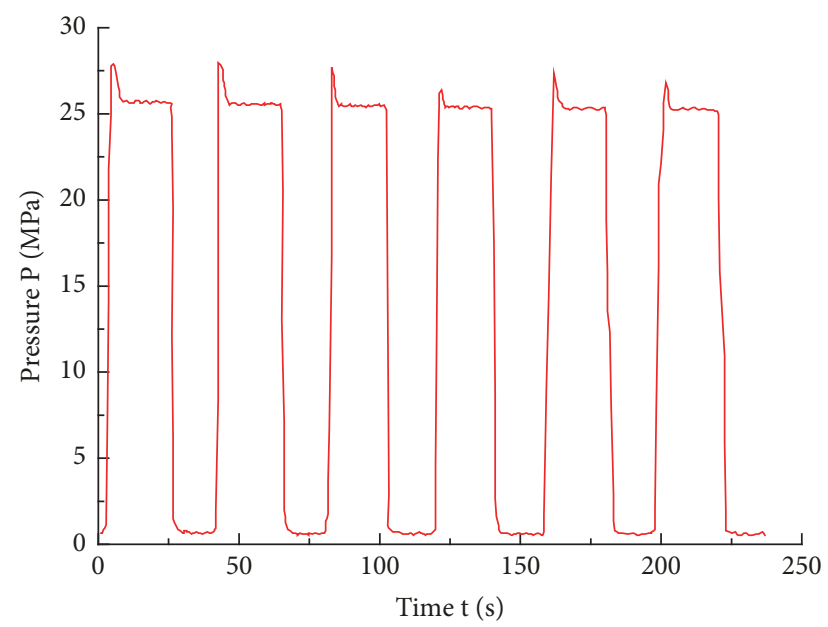

FIGURE 16: Result curve of impact test.

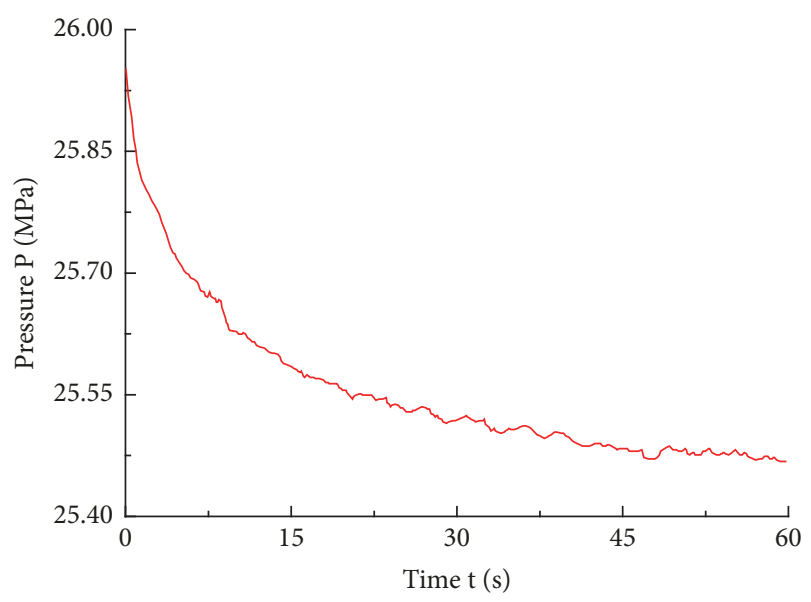

FIGURE 17: Result curve of full-load test.

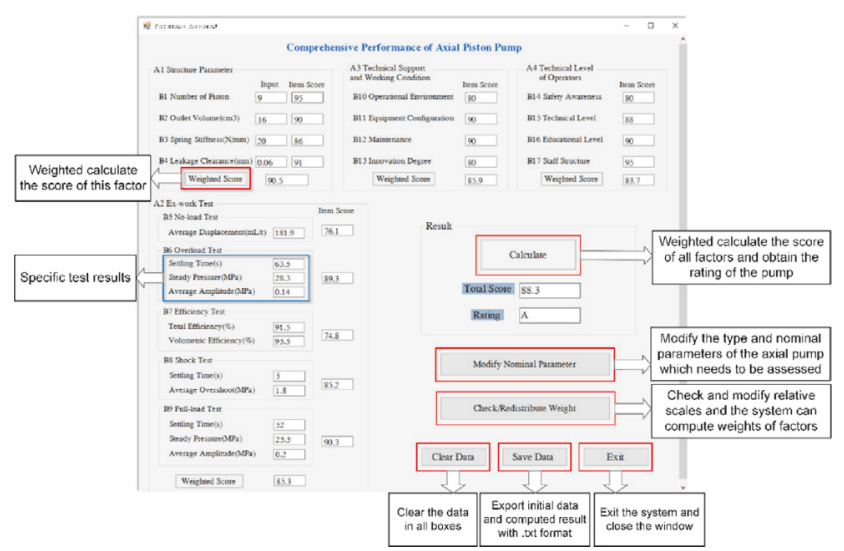

FIGURE 18: Interface of comprehensive evaluation software.

each level, and the marking criterion and calculation formula of factors were embedded in the software, which reduced the complex calculation process. For the indexes $\mathrm{A} 1$ and $\mathrm{A} 2$, users were required to input the relevant structural parameters and test results of the tested pump and the software calculated each item score automatically; for the indexes of A3 and A4, the item scores were required to be input directly after analysis owing to the unfixed calculation method and quantity of input. The software system could calculate the weighted scores of the indexes and the entire system and obtain the performance rating of the tested pump. The functions of modifying the nominal parameters of the tested pump, redistributing the calculating weights, clearing the data in table, and saving the scores and evaluation result could be accomplished using different buttons on the interface.

\section{Conclusions}

The theoretic simulation demonstrated that, in order to improve the performance of an axial piston pump, (1) the number of pistons should not be too small, but a pump with too many pistons has a large overshoot, which could cause impacts and vibration; (2) the increase in outlet volume could increase the operation stability but too large volume 
can prolong the settling time; (3) when the spring stiffness of the locating cylinder was too small, the increased overshoot may result in hydraulic impact; however, an excessively large stiffness may cause a decrease in flow rate and lack of stability; (4) the leakage clearance significantly influenced the performance of the piston pump, and the machining precision should be improved to reduce the clearance. The ex-work test was conducted for the tested pump using the designed and built test bed. The test results showed that the test bed can satisfy the test requirements of axial piston pump performance and collect accurate performance test results.

Based on the designed evaluation system for comprehensive performance, the tested pump was analyzed with the results from simulation and testing and the investigation from the application site, and an evaluation software was developed to simplify the process of analyzing and calculating. The evaluation result was basically identical to the actual usage, which showed that the system can evaluate the performance of a piston pump comprehensively and objectively.

In this study, an evaluation system for the comprehensive performance of an axial piston pump was developed based on AHP, which had an actual guiding significance to the structure design, production, and field application of the axial piston pump. In actual application, the evaluation system should be adjusted corresponding to the model of the tested pump and specific requirements to obtain accurate evaluation results.

\section{Data Availability}

The results of simulation, performance test, and calculation are shown in the figures of the article; therefore, the data used to support the findings of this study are included within the article.

\section{Conflicts of Interest}

The authors declare no conflicts of interest.

\section{Acknowledgments}

This work was supported by the National Natural Science Fund of China (Grant no. 51674155), Innovative Team Development Project of Ministry of Education (Grant no. IRT_16R45), Natural Science Foundation of Shandong Province (Grant no. ZR2016EEM02), and the Qingdao Postdoctoral Application Research Project (no. 2016120).

\section{References}

[1] Y. Lin, W. Liang, Z. Qiu, M. Zhang, and W. Lu, "A new state evaluation method of oil pump unit based on AHP and FCE," in Proceedings of the 12th International Conference on Damage Assessment of Structures, 2017.

[2] Z. L. Lin, G. Zheng, G. L. Mo, J. L. Wang, and J. G. Cui, "Prediction of aircraft hydraulic pump fault based on fuzzy comprehensive evaluation," Journal of Vibration, Measurement \& Diagnosis, vol. 36, no. 4, pp. 746-750, 2016.

[3] B. Jikun, L. Chen, W. Zhipeng, and W. Zili, "An approach to performance assessment and fault diagnosis for hydraulic pumps," Journal of Vibroengineering, vol. 16, no. 3, pp. 14441454,2014

[4] J. Selvakumar and K. Natarajan, "Reliability analysis of centrifugal pump through FMECA and FEM," International Journal of Performability Engineering, vol. 13, no. 2, pp. 119-128, 2017.

[5] X. Tao, C. Lu, C. Lu, and Z. Wang, "An approach to performance assessment and fault diagnosis for rotating machinery equipment," EURASIP Journal on Advances in Signal Processing, vol. 2013, no. 1, 2013.

[6] Y. Ding, J. Ma, and Y. Tian, "Health assessment and fault classification for hydraulic pump based on LR and softmax regression," Journal of Vibroengineering, vol. 17, no. 4, pp. 1805-1816, 2015.

[7] S. L. Sun, P. W. Tse, and Y. L. Tse, "An Enhanced Factor Analysis of Performance Degradation Assessment on Slurry Pump Impellers," Shock and Vibration, vol. 2017, Article ID 1524840, 13 pages, 2017.

[8] H.-X. Cui, K. Feng, H.-L. Li, and J.-H. Han, "Response Characteristics Analysis and Optimization Design of Load Sensing Variable Pump," Mathematical Problems in Engineering, vol. 2016, Article ID 6379121, 10 pages, 2016.

[9] A. Roccatello, S. Mancò, and N. Nervegna, "Modelling a Variable Displacement Axial Piston Pump in a Multibody Simulation Environment," Journal of Dynamic Systems Measurement \& Control, vol. 129, no. 4, pp. 819-829, 2007.

[10] B. Zhang, B. Xu, C. L. Xia, and H. Y. Yang, "Modeling and simulation on axial piston pump based on virtual prototype technology," Chinese Journal of Mechanical Engineering, vol. 22, no. 1, pp. 84-90, 2009.

[11] J. E. Ma, B. Xu, B. Zhang, and H. Yang, "Flow Ripple of Axial Piston Pump with Computational Fluid Dynamic Simulation Using Compressible Hydraulic Oil," Chinese Journal of Mechanical Engineering, vol. 23, no. 1, pp. 45-52, 2010.

[12] B. Xu, J. Zhang, H. Yang, and B. Zhang, "Investigation on the radial micro-motion about piston of axial piston pump," Chinese Journal of Mechanical Engineering, vol. 26, no. 2, pp. 325-333, 2013.

[13] B. Xu, M. Hu, and J. Zhang, "Impact of typical steady-state conditions and transient conditions on flow ripple and its test accuracy for axial piston pump," Chinese Journal of Mechanical Engineering, vol. 28, no. 5, pp. 1012-1022, 2015.

[14] B. Xu, J. Zhang, and H. Yang, "Simulation research on distribution method of axial piston pump utilizing pressure equalization mechanism," Proceedings of the Institution of Mechanical Engineers, Part C: Journal of Mechanical Engineering Science, vol. 227, no. 3, pp. 459-469, 2013.

[15] R. Guo, C. Ning, J. Y. Zhao, P. Wang, and Y. Shi, "Life prediction and test period optimization research based on small sample reliability test of hydraulic pumps," High Technology Letters, vol. 23, no. 1, pp. 63-70, 2017.

[16] X. Z. Wang, Y. Lu, and S. H. Zheng, "Novel method for operating characteristics test of a hydraulic pump," Journal of Beijing Institute of Technology, vol. 24, no. 1, pp. 74-82, 2015.

[17] K. Dasgupta and S. K. Mondal, "Analysis of the steady-state performance of a multi-plunger hydraulic pump," Proceedings of the Institution of Mechanical Engineers Part A Journal of Power \& Energy, vol. 216, pp. 471-479, 2002.

[18] J. H. Zhang, Q. Chao, Q. N. Wang, B. Xu, Y. Chen, and Y. $\mathrm{Li}$, "Experimental investigations of the slipper spin in an axial piston pump," Measurement, vol. 102, 2017. 
[19] Y. Q. Yan, Z. Q. Shi, and L. Zheng, "Analysis of Influence Factors for axial piston hydraulic pump flow fluctuation based on Amesim," Chinese Hydraulic \& Pneumatics, pp. 104-108, 2014.

[20] A. S. Al-Harbi, "Application of the AHP in project management," International Journal of Project Management, vol. 19, no. 1, pp. 19-27, 2001.

[21] J. Zhang, T. Z. Zhang, L. J. Cheng, and Y. L. Li, "Dynamic simulation research based on Amesim about load sensitive pump of excavator," Journal of Qingdao University (E \& T), vol. 30, no. 1, pp. 99-104, 2015. 


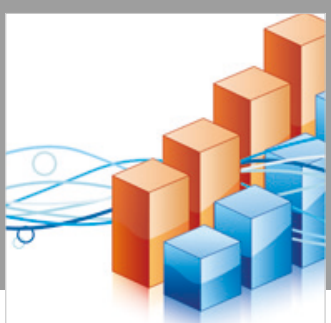

Advances in

Operations Research

\section{-n-m}
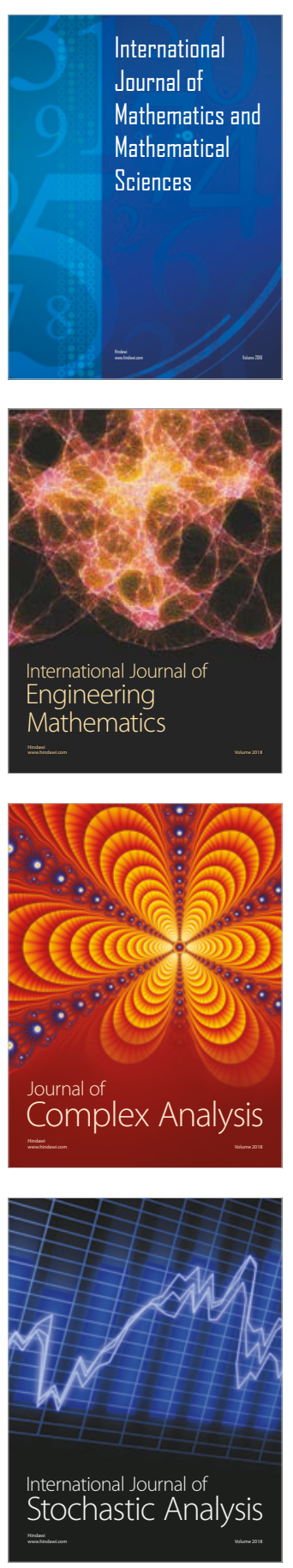
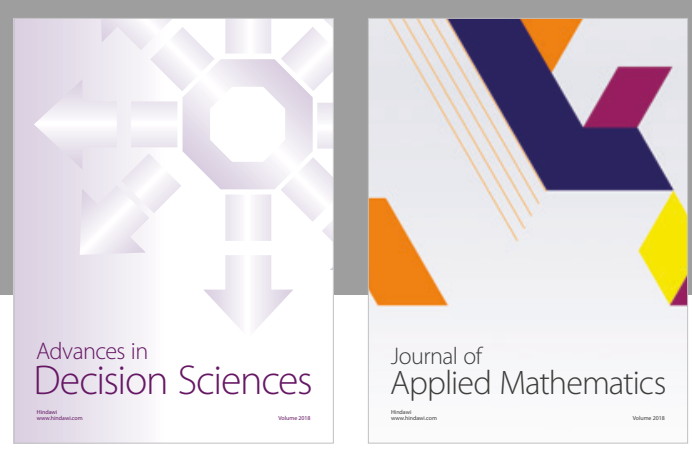

Journal of

Applied Mathematics
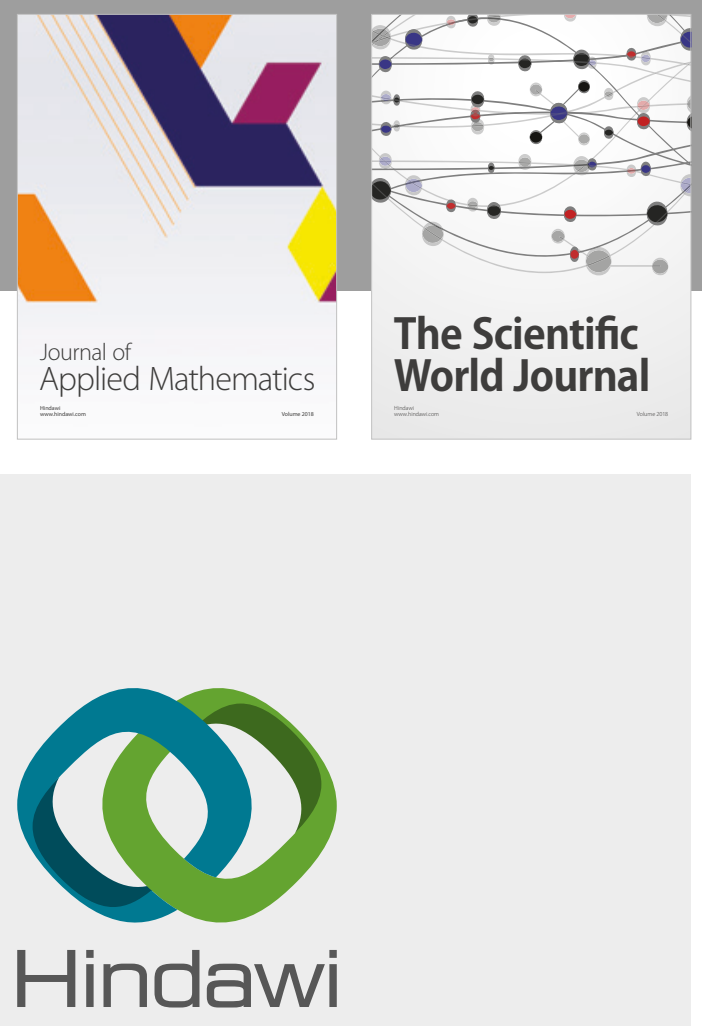

Submit your manuscripts at

www.hindawi.com

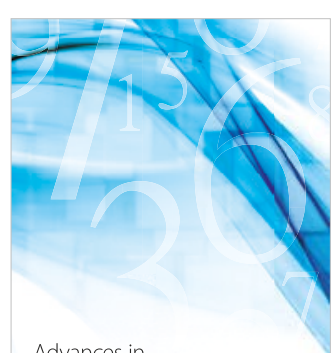

Advances in
Numerical Analysis
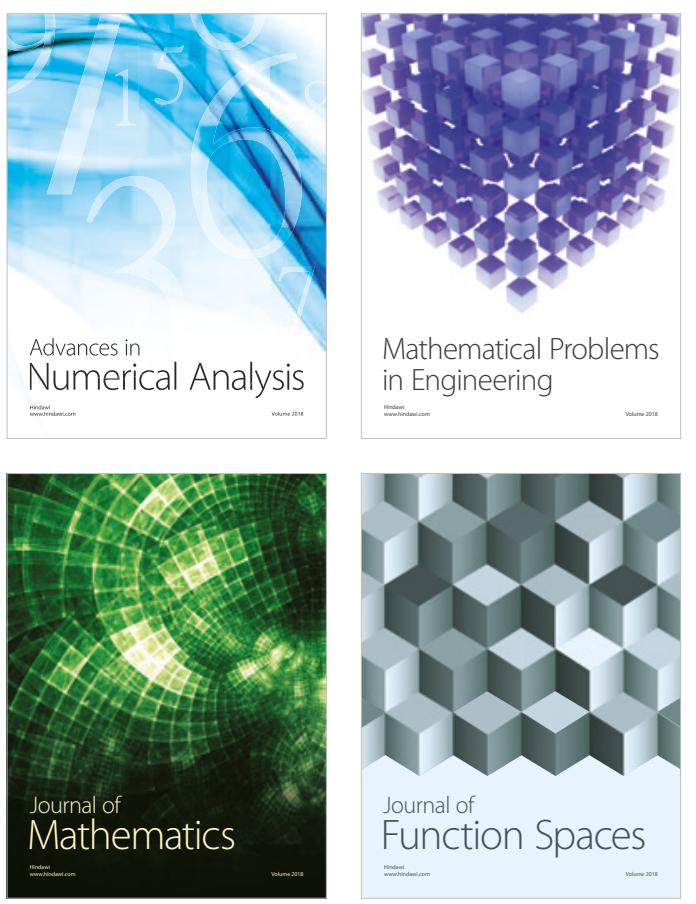

Mathematical Problems in Engineering

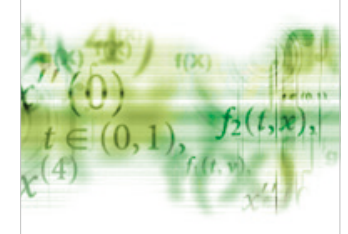

International Journal of

Differential Equations

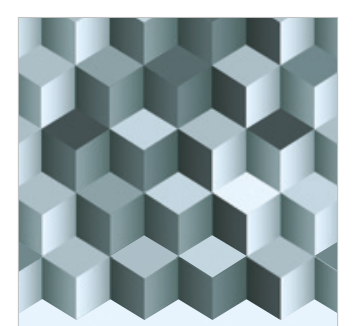

Journal of

Function Spaces

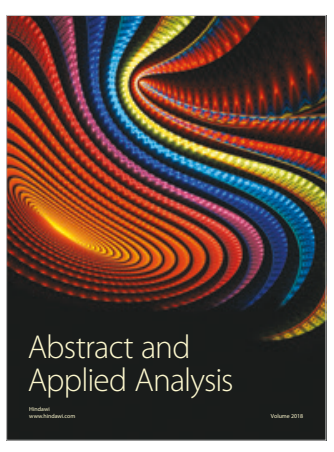

The Scientific

World Journal

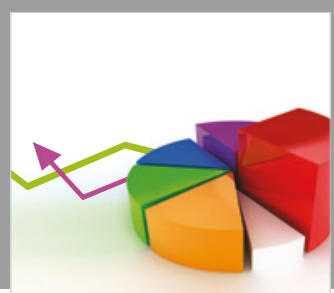

Journal of

Probability and Statistics
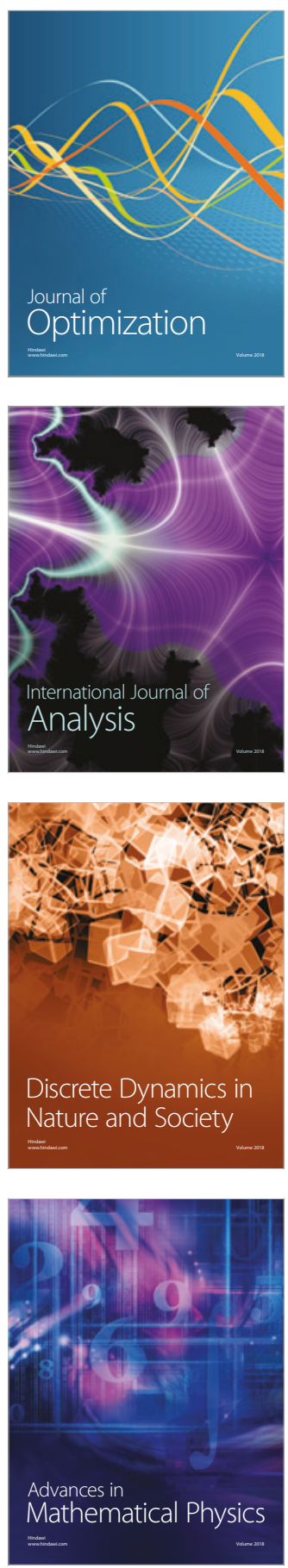